Article

\title{
Cascade Type-I Quantum Well GaSb-Based Diode Lasers
}

\author{
Leon Shterengas *, Gela Kipshidze, Takashi Hosoda, Meng Wang, Tao Feng and Gregory Belenky \\ Department of Electrical and Computer Engineering, State University of New York at Stony Brook, \\ Stony Brook, NY 11794, USA; gela.kipshidze@stonybrook.edu (G.K.); takashi.hosoda@stonybrook.edu (T.H.); \\ meng.wang.2@stonybrook.edu (M.W.); tao.feng@stonybrook.edu (T.F.); gregory.belenky@stonybrook.edu (G.B.) \\ * Correspondence: leon.shterengas@stonybrook.edu; Tel.: +1-631-632-9376
}

Received: 7 April 2016; Accepted: 4 May 2016; Published: 11 May 2016

\begin{abstract}
Cascade pumping of type-I quantum well gain sections was utilized to increase output power and efficiency of GaSb-based diode lasers operating in a spectral region from 1.9 to $3.3 \mu \mathrm{m}$. Carrier recycling between quantum well gain stages was realized using band-to-band tunneling in $\mathrm{GaSb} / \mathrm{AlSb} / \mathrm{InAs}$ heterostructure complemented with optimized electron and hole injector regions. Coated devices with an $\sim 100-\mu \mathrm{m}$-wide aperture and a 3-mm-long cavity demonstrated continuous wave (CW) output power of $1.96 \mathrm{~W}$ near $2 \mu \mathrm{m}, 980 \mathrm{~mW}$ near $3 \mu \mathrm{m}, 500 \mathrm{~mW}$ near $3.18 \mu \mathrm{m}$, and $360 \mathrm{~mW}$ near $3.25 \mu \mathrm{m}$ at $17-20^{\circ} \mathrm{C}$-a nearly or more than twofold increase compared to previous state-of-the-art diode lasers. The utilization of the different quantum wells in the cascade laser heterostructure was demonstrated to yield wide gain lasers, as often desired for tunable laser spectroscopy. Double-step etching was utilized to minimize both the internal optical loss and the lateral current spreading penalties in narrow-ridge lasers. Narrow-ridge cascade diode lasers operate in a CW regime with $\sim 100 \mathrm{~mW}$ of output power near and above $3 \mu \mathrm{m}$ and above $150 \mathrm{~mW}$ near $2 \mu \mathrm{m}$.
\end{abstract}

Keywords: high power; mid-infrared; diode laser; antimonide; type-I quantum well; cascade

\section{Introduction}

Cascade pumping originally proposed in [1] became recognized as a carrier delivery scheme leading to high-power room temperature continuous wave operation of semiconductor lasers utilizing gain sections based on electron transitions between subbands in the conduction band-quantum cascade lasers (QCLs) [2,3] —and interband transitions in the type-II quantum well—interband cascade lasers (ICLs) [4]. Thus, a series connection of an optimized number of aforementioned or any other quantum well $(\mathrm{QW})$ gain sections is arguably a fundamental advantage of the cascade lasers over non-cascade multiple-QW devices. In multiple- $\mathrm{QW}$ diode lasers, the carrier transport considerations (such as buildup of the transparency current and development of pumping inhomogeneity often causing the degradation of both differential gain and injection efficiency) often dwarf a positive impact of an increased number of active QWs and, in certain cases, restrict the height of carrier localization barriers in individual QWs degrading temperature stability of laser parameters. Another benefit of cascade pumping includes the redistribution of the voltage drop across auxiliary layers of the laser heterostructure over multiple active regions, leading to improvement of the overall power conversion efficiency. This is closely related to the scaling of the laser slope efficiency with the number of cascades and also helps to increase the output power available before the thermal rollover of light-current characteristics. Arguably, the utilization of series rather than parallel connection of the type-I QWs gain sections, i.e., their cascade pumping, should enhance the performance characteristics of diode lasers.

Monolithic integration of two GaAs-based type-I QW diode lasers connected in series by means of doped tunnel junction was demonstrated [5], leading to a nearly twofold an increase in overall device efficiency. Though the optical mode was not shared by two lasers in that design, the close 
location of two near-fields offered certain benefits (for instance, it could ease a fiber coupling). True cascade pumping of the type-I QW gain sections coupled to the same transverse optical mode was reported for InP-based diode lasers (see, for instance, [6]). The cascade pumping was realized through the introduction of the doped pn junction that became tunnel transparent under reverse bias. High operating voltage and/or high absorption loss associated with coupling of the tunnel pn junction to the modal field overcame the benefit of carrier recycling. Cascade-pumped GaSb-based vertical cavity surface-emitting lasers (VCSELs) with tunnel junction placed at the node of the optical field in order to minimize the detrimental effect of the strong absorption on device threshold and efficiency were reported [7]. Though rather convenient for VCSELs, this approach is not efficient for the development of high-power edge emitting lasers since it would necessitate the device operation at higher-order transfer modes producing multiple-lobe divergent far-field patterns. Broken gap band alignment at the heterointerface between InAs and GaSb was proposed [8] for design of GaSb-based cascade bipolar devices. Efficient band-to-band tunneling at GaSb/InAs heterointerface can be realized without excessive doping and, hence, without a severe free carrier absorption penalty. This unique feature enabled the high-power operation of the type-II QW ICL [4] and can be viewed as a critical advantage of the GaSb-based material system for the development of high-power type-I QW lasers emitting in a spectral region from below 2 to over $3 \mu \mathrm{m}$.

We proposed and demonstrated a high-power GaSb-based type-I QW cascade diode lasers emitting near $3 \mu \mathrm{m}$ at room temperature in a CW regime [9]. Figure 1a shows schematically the generic two-stage laser heterostructure band diagram. The electrons are injected from n-cladding into the GaInAsSb QW1 of the first gain section. The electron-hole recombination in the QW1 is followed by interband tunneling, which transfers the electrons from the barrier valence band of the first gain section to the conduction band of the second gain section. The electron transfer between stages takes place at the tunnel junction located in the center of the waveguide core (insert to Figure 1a). The junction was made of a 10-nm-thick GaSb layer, 2.5-nm-thick AlSb, and a first InAs QW of the chirped InAs / AlSb superlattice (SL) (similar to the ICL [4]). The AlGaAsSb 100-nm-wide graded composition layer was introduced after the QW1 to stop the electron and to promote the hole transport. Chirped AlSb/InAs SL stopped hole transport from QW2 and promoted the electron transport to QW2.

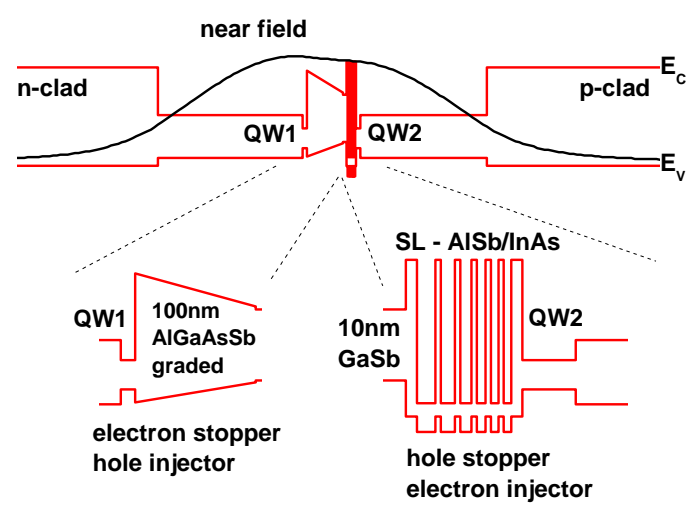

(a)

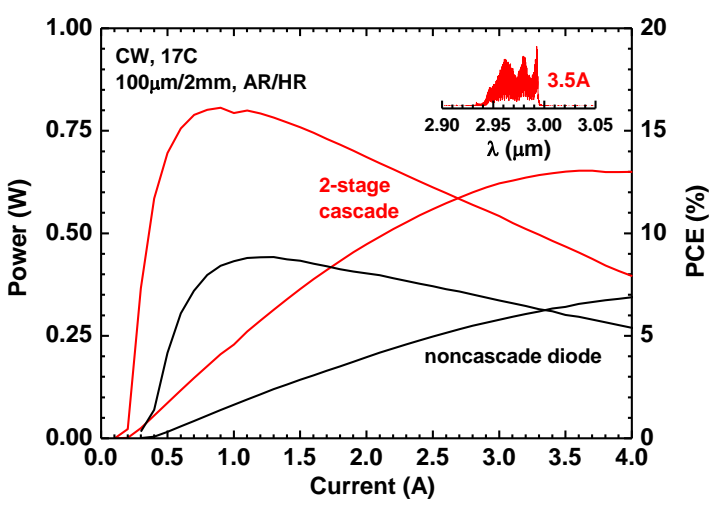

(b)

Figure 1. (a) Schematic band diagram of the two-stage GaSb-based type-I quantum well (QW) cascade diode lasers. Insert magnifies the parts of laser heterostructure responsible for electron transfer from valence band of QW1 to the conduction band of QW2. (b) CW light-current and power conversion characteristics measured at $1{ }^{\circ} \mathrm{C}$ for 100 - $\mu \mathrm{m}$-wide, 2-mm-long, anti-/high-reflection coated two-stage cascade and reference diode lasers [9]. Insert shows the cascade device emission spectra corresponding to the maximum power level.

Figure $1 \mathrm{~b}$ shows the $\mathrm{CW}$ light-current and power-conversion characteristics of the $100-\mu \mathrm{m}$-wide, 2-mm-long, anti-/high-reflection (AR/HR) coated two-stage cascade lasers together with those 
of the reference double-QW diode lasers. Twofold carrier recycling led to a nearly twofold improvement of the laser output power level and peak power conversion efficiency as well as to a twofold reduction in the threshold current density-all in accordance with theoretical predictions. Narrow-ridge lasers fabricated from the same wafer demonstrated more than $100 \mathrm{~mW}$ of output power in a nearly diffraction-limited beam [10]. Laterally coupled distributed-feedback 2.9- $\mu \mathrm{m}$ lasers for hydroxyl radicals spectroscopy were based on a similar two-stage cascade laser heterostructure and demonstrated $\mathrm{CW}$ power above $10 \mathrm{~mW}$ in a stable single spectral mode beam [11]. An increase in the number of cascades to three yielded high-power multimode $\lambda \sim 3-\mu \mathrm{m}$ lasers with a record $\mathrm{CW}$ output power level of $960 \mathrm{~mW}$ from a 100- $\mu \mathrm{m}$-wide aperture at room temperature [9]. It should be noted that type-I QW emitters based on standard ICL heterostructures with two n-claddings and operating at a similar wavelength were reported [12], but these devices were still demonstrated to have much lower output power levels.

Cascade pumping can enhance performance parameters of GaSb-based type-I QW diode lasers operating not only near $3 \mu \mathrm{m}$ but also those operating in wide spectral region from 1.9 to $3.5 \mu \mathrm{m}$ and, perhaps, can extend the operating wavelength range of this laser technology into a spectral region near and above $4 \mu \mathrm{m}$. The applications for lasers operating in spectral region 1.9-2.5 $\mu \mathrm{m}$ include resonant pumping of the holmium-doped laser hosts near $1.95 \mu \mathrm{m}$ [13], LIDAR seeding near $2.05 \mu \mathrm{m}$ [14], and glucose tunable laser spectroscopy (TLS) near $2.3 \mu \mathrm{m}$. Compact efficient emitters operating in a spectral region near and above $3 \mu \mathrm{m}$ find many applications in TLS, including methane monitoring near $3.25 \mu \mathrm{m}$. Recent results on the application of the cascade pumping scheme to the development of high-power and single-spatial-mode GaSb-based type-I QW lasers operating in a wide spectral region are discussed in this work.

\section{Materials and Methods}

Laser heterostructures were grown on Te-doped GaSb substrates by solid source molecular beam epitaxy using GEN 930 modular system equipped with valved cracker cells for As and $\mathrm{Sb}$. The devices used $\sim 1.5$ - $\mu \mathrm{m}$-thick $(\lambda \sim 2 \mu \mathrm{m})$ and $\sim 2$ - $\mu \mathrm{m}$-thick $(\lambda \sim 3 \mu \mathrm{m}) \mathrm{Al}_{0.8} \mathrm{Ga}_{0.2} \mathrm{As}_{0.07} \mathrm{Sb}_{0.93}$ cladding layers doped with Te and Be for $\mathrm{n}$ - and p-types, respectively. Devices emitting above $3 \mu \mathrm{m}$ utilized $~ 13$-nm-wide GaInAsSb QWs with nominal In composition in the range from 55 to $58 \%$ and a compressive strain of $\sim 1.5 \%$, while lasers emitting near $2 \mu \mathrm{m}$ used $\sim 8$-nm-wide $\mathrm{Ga}_{0.75} \mathrm{In}_{0.25} \mathrm{Sb}$ QWs. The waveguide structure of all devices was similar to the one shown in Figure 1a unless specifically noted. Devices emitting above $3 \mu \mathrm{m}$ utilized $400 \mathrm{~nm}$ and $350 \mathrm{~nm}$ of $\mathrm{Al}_{0.3} \mathrm{Ga}_{0.4} \mathrm{In}_{0.3} \mathrm{As}_{0.28} \mathrm{Sb}_{0.72}$ alloys between n-cladding and the beginning of a cascade pumped type-I QW stack and between the end of the stack and p-cladding, respectively. Lasers operating near $2 \mu \mathrm{m}$ used $400 \mathrm{~nm}$ of $\mathrm{Al}_{0.3} \mathrm{Ga}_{0.7} \mathrm{As}_{0.03} \mathrm{Sb}_{0.97}$ alloys on both sides of the active region to form a separate confinement heterostructure. Details of the laser heterostructure designs can be found in $[9,15,16]$. Wafers were processed either into $100-\mu \mathrm{m}$-wide deep-etched (through waveguide core) ridges for high-power operation or into double-step shallow-/deep-etched narrow ridges for single-spatial-mode operation. $\mathrm{Si}_{3} \mathrm{~N}_{4}$ dielectric and $\mathrm{Ti} / \mathrm{Pt} / \mathrm{Au}$ final metallization were utilized. Uncoated 1-mm-long lasers were indium-soldered epi-up onto gold plated copper blocks for pulsed ( $200 \mathrm{~ns} / 100 \mathrm{kHz}$ ) characterization. Coated 2- and 3-mm-long lasers were soldered either epi-up or epi-down using indium. Facet coating was performed using single layer quarter-wavelength $\mathrm{Al}_{2} \mathrm{O}_{3}$ to form $\mathrm{AR}$ (reflectivity 3\%-5\%) and two-period $\mathrm{Al}_{2} \mathrm{O}_{3} / \mathrm{Si}$ Bragg reflector to form $\mathrm{HR}$ (reflectivity $>95 \%)$ mirrors.

\section{Results and Discussion}

\subsection{Devices Emitting above $3 \mu \mathrm{m}$}

An increase in the operating wavelength of the type-I QW GaSb-based laser into a spectral region above $3 \mu \mathrm{m}$ is expected to be accompanied by a fundamental enhancement of the Auger recombination and free carrier absorption rates, as well as material-specific reduction of the hole 
confinement barriers [17]. The attempt to utilize the same two-stage laser heterostructure, as was used for $\lambda \sim 3 \mu \mathrm{m}$ emitters (Figure 1) but with the QW indium composition increased to $\sim 55 \%$, yielded 3.15-3.2- $\mu \mathrm{m}$ lasers with a twofold improvement of slope efficiency compared to reference diodes. However, there was no improvement in terms of threshold current density and maximum CW output power [16]. Modal gain measurements revealed that the two-stage cascade lasers where $\lambda>3 \mu \mathrm{m}$ suffer from gain saturation. The experiment showed [15] that the increase in the number of cascades from two to three led to a critical enhancement of the differential gain and reduction in the threshold current density of $\lambda>3-\mu \mathrm{m}$ lasers. Light p-doping of the AlGaAsSb graded section did not introduce extra optical loss but aided hole transport, as required for the realization of the efficient multi-stage cascade pumping scheme. Corresponding coated three-stage devices with an $\sim 100-\mu \mathrm{m}$-wide aperture and a 3-mm-long cavity demonstrated $\mathrm{CW}$ output power of $500 \mathrm{~mW}$ near $3.18 \mu \mathrm{m}$ at $17^{\circ} \mathrm{C}$-a more than twofold increase compared to previous state-of-the-art diode lasers emitting $200 \mathrm{~mW}$ (Figure 2a). The device threshold current density was about $200 \mathrm{~A} / \mathrm{cm}^{2}$. These parameters were achieved using lasers soldered epi-down with indium directly onto gold-plated copper blocks. Coated 3-mm-long devices demonstrated parameters $\mathrm{T}_{0}$ and $\mathrm{T}_{1}$ of $\sim 45 \mathrm{~K}$ and $\sim 80 \mathrm{~K}$, respectively, as measured in a low-duty cycle regime $(200 \mathrm{~ns} / 100 \mathrm{kHz})$ in a temperature range from 15 to $60^{\circ} \mathrm{C}$.

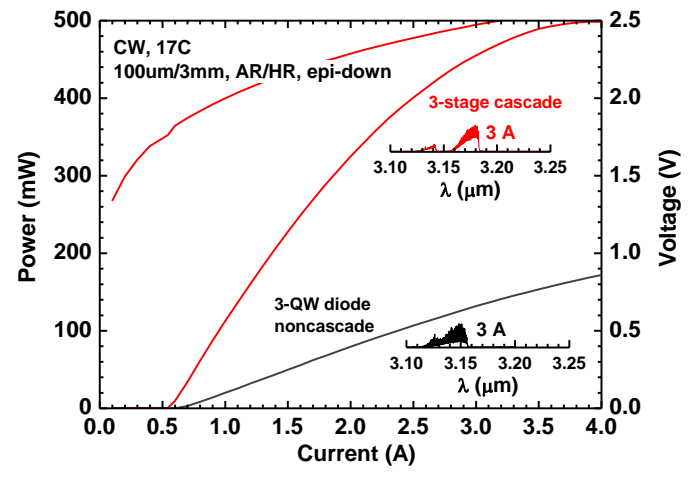

(a)

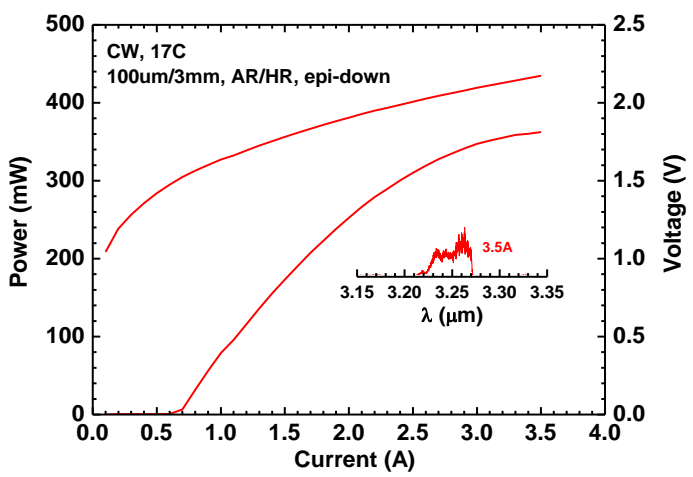

(b)

Figure 2. CW light-current characteristics measured at $17^{\circ} \mathrm{C}$ for $100-\mu \mathrm{m}$-wide, 3-mm-long, coated three-stage cascade diode lasers emitting at (a) $\lambda \sim 3.15-3.2 \mu \mathrm{m}$ [15], and data for reference non-cascade diode laser is also shown; (b) $\lambda \sim 3.25 \mu \mathrm{m}$. Inserts show the device's emission spectra.

In order to extend the operating wavelength of the three-stage cascade lasers into a technologically important spectral region of the methane absorption, we further increased the indium composition of active QWs to about $58 \%$. The laser heterostructure was similar to three-stage designs used for the development of 3.15-3.2- $\mu$ m emitters except for the AlGaInAsSb layer between n-cladding and QW1, being replaced with lightly tellurium-doped GaSb. The hole confinement in QW1 was achieved by adding an InAs/AlSb superlattice insert between GaSb and QW1. The devices demonstrated an internal optical loss of 6-7- $\mathrm{cm}^{-1}$ as determined by the Hakki-Paoli gain measurements and record low (for lasers operating in this spectral region) threshold current densities of $\sim 250 \mathrm{~A} / \mathrm{cm}^{2}$. Figure $2 \mathrm{~b}$ shows light-current-voltage characteristics measured in a CW regime for 100- $\mu \mathrm{m}$-wide, 3-mm-long, coated three-stage cascade lasers. A more than threefold improvement of output power compared to previously reported non-cascade diodes [18] was demonstrated with the three-stage modified cascade design, leading to a record 360-mW output power level near $3.25 \mu \mathrm{m}$. The voltage drop across the laser heterostructure was about $2.2 \mathrm{~V}$ at the current of $3.5 \mathrm{~A}$, corresponding to the maximum $\mathrm{CW}$ output power level. Peak power conversion efficiency was near $7 \%$.

It should be noted that cascade pumping scheme allows for easy integration of the active regions with a slightly different gain spectrum into laser heterostructure, helping to achieve a wide net optical gain spectrum. Since each of the QWs is separated by an injector region, they do not compete for pumping current and can be separately designed to contribute to laser optical gain in different regions 
of spectra. This flexibility in gain shaping related to the cascade pumping scheme can yield efficient external cavity lasers with a wide tuning range, offering critical benefits to various tunable laser spectroscopy applications. Figure 3 plots light-current-voltage characteristics and modal optical gain measured for three stage cascade lasers containing three slightly different QWs, yielding wide optical gain peak. In the example of Figure $3 \mathrm{~b}$, the gain spectra peak near $0.39 \mathrm{eV}$ after transparency, and then it shifts to $\sim 0.41 \mathrm{eV}$ with pumping current. This leads to device operation at very different wavelengths for different net cavity loss levels. Inserts to Figure 3a,b show the emission spectra of 1-mm- and 2-mm-long lasers made of this wafer. Since 2-mm-long devices have about $6 \mathrm{~cm}^{-1}$ lower total loss compared to 1-mm-long lasers, the lower pumping current yields gain peak at longer wavelengths. At a certain pumping level, the gain spectrum has a wide flat region, implying a virtually unchanged threshold current for lasers with a corresponding emission wavelength if selected by an external cavity element such as diffraction grating.

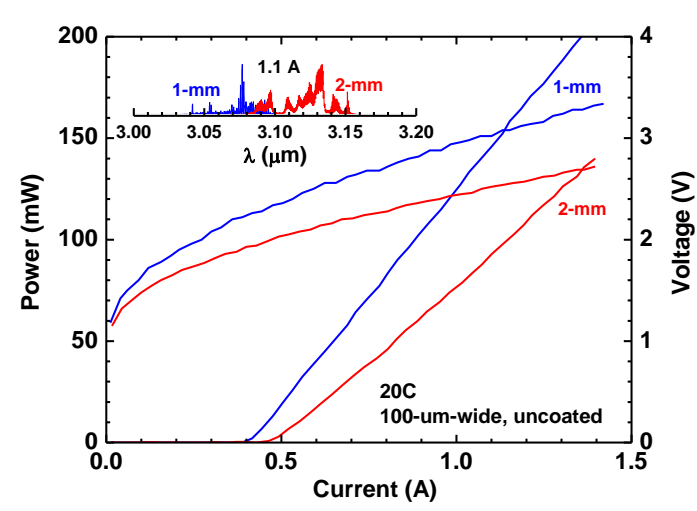

(a)

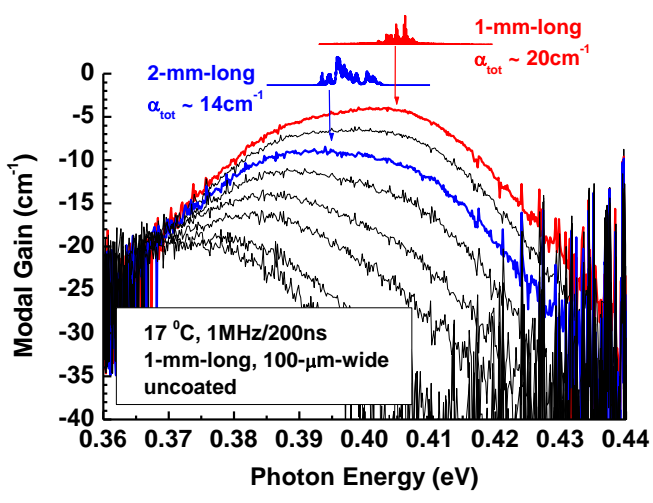

(b)

Figure 3. (a) Short pulse light-current-power conversion characteristics measured at $20{ }^{\circ} \mathrm{C}$ for 100- $\mu \mathrm{m}$-wide, 1-mm-long, uncoated three-stage cascade lasers. Insert shows the device's emission spectra. (b) Modal gain spectra measured by the Hakki-Paoli method for 1-mm-long, uncoated wide-gain three-stage cascade diode lasers under pulsed excitation (200 ns/1 MHz). Inserts show the emission spectra of free-running Fabry-Perot lasers with 1- and 2-mm-long cavities, hence requiring different threshold gains.

The utilization of the benefits of cascade diode laser technology in the field of tunable laser spectroscopy (TLS) requires the development of a robust method for the fabrication of efficient devices with a diffraction limited beam. One classic approach to produce single-spatial-mode diode lasers is based on etching the narrow-ridge to confine mode in a lateral direction. Our studies of the shallow ridge waveguide two-stage cascade diode lasers demonstrated that the utilization of the ridge geometry that was nearly optimal for non-cascade multiple-QW diode lasers [19] led to excessive lateral current spreading penalty [10]. Efficient device operation in a spectral region above $3 \mu \mathrm{m}$ requires more than two cascades, and an increase in the number of cascades increases the tendency to lateral current spreading. Deep etching through the interband gain section confines the current well but often signifies the role of the parasitic surface recombination current and can increase internal losses in narrow-ridge designs or promote multimode operation when wider ridges are used. One possible solution is based on a separate lateral confinement structure in which a wide deep ridge confines the current, while a narrow shallow ridge forms a modal field. It was demonstrated that this approach can dramatically improve performance parameters of the interband cascade, laterally coupled distributed-feedback lasers [20]. It should be noted that in case of tunnel-junction vertical cavity surface-emitting lasers based on $\mathrm{GaSb}$, the lateral current spreading promoted by a $\mathrm{GaSb} / \mathrm{GaSb}$ pn junction was utilized to guide the current into the aperture defined by a heavily doped $\mathrm{GaSb} / \mathrm{InAs}$ tunnel junction (see, for instance, [21]). 
We studied the effect of the width of the deep-etched and etching depth of the shallow ridges on threshold current and fundamental mode stability in a three-stage cascade type-I QW double-step ridge lasers. Figure 4a shows the example of a cross-sectional scanning electron microscope (SEM) image of the double-step ridge waveguide structure with a shallow ridge width of $\sim 5 \mu \mathrm{m}$ and a deep-etched section of variable width. In our experiments, the width of the deep-etched ridge varied from $\sim 10$ to $\sim 30 \mu \mathrm{m}$. A strong tendency to lateral current spreading was confirmed by a dependence of the threshold current on the width of the deep-etched section in devices with a fixed geometry of the shallow-etched ridge. The threshold current nearly perfectly scales with the deep-etched width reduction from 100 to $20 \mu \mathrm{m}$. A further reduction in the deep-etched section width does not reduce the threshold current, presumably due to an increased role of the recombination current and scattering loss at the etched ridge sidewalls. It should be noted that the experiment shows, and modeling confirms, that the wide deep-etched section does affect the fundamental mode shape, and the lateral far-field divergence angle decreases with an increasing wide-ridge section width (Figure 4c).

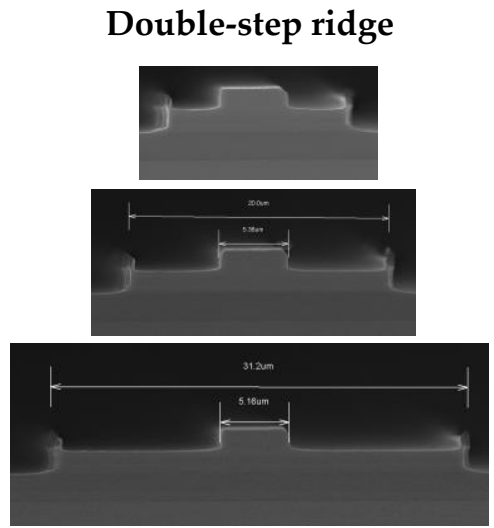

(a)

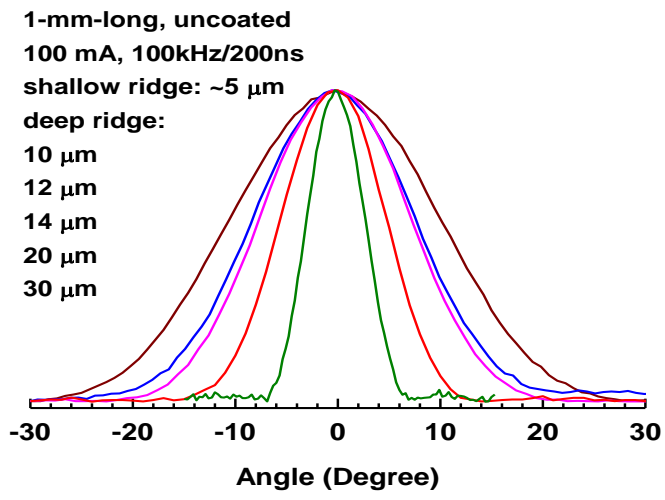

(c)

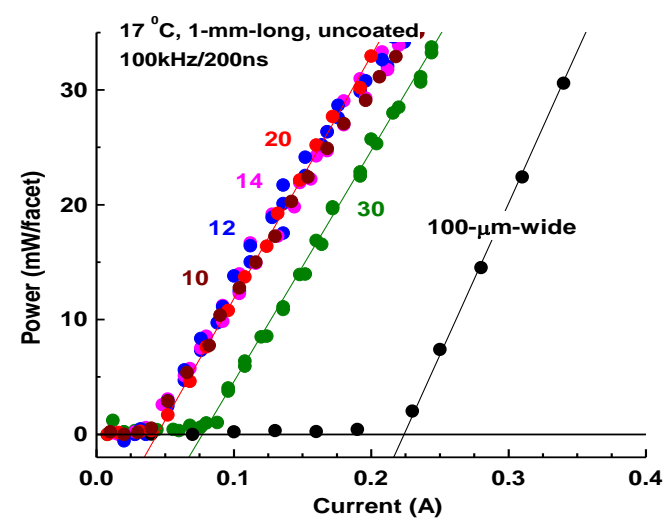

(b)

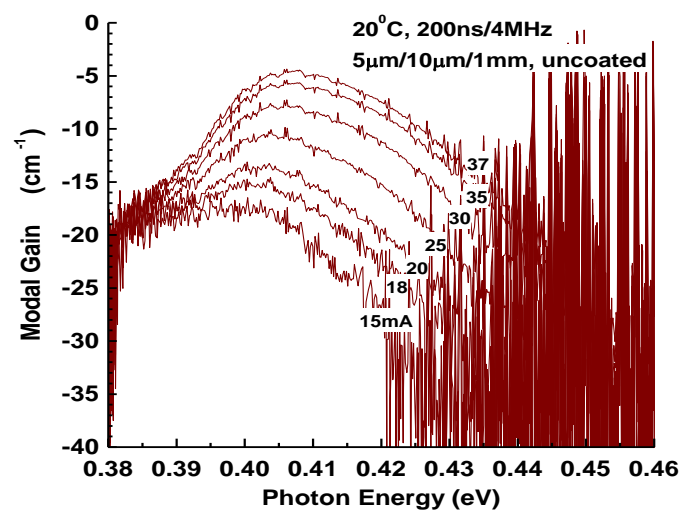

(d)

Figure 4. (a) Cross-sectional scanning electron microscope image of the two-step ridge waveguide structure with a shallow ridge width of $\sim 5 \mu \mathrm{m}$ and deep-etched section widths of $\sim 14, \sim 20$, and $\sim 30 \mu \mathrm{m}$ (image is taken prior to dielectric deposition and metallization). (b) Light-current characteristics measured at $17^{\circ} \mathrm{C}$ in a short-pulse regime $(200 \mathrm{~ns} / 100 \mathrm{kHz})$ for $1 \mathrm{~mm}$-long, 100- $\mathrm{mm}$-wide, uncoated double-step ridge waveguide three-stage cascade lasers with a 5 - $\mu \mathrm{m}$-wide shallow ridge and deep ridge width ranging from 10 to $30 \mu \mathrm{m}$. Reference LI is measured for 100- $\mu \mathrm{m}$-wide single-step deep-ridge lasers. (c) Slow axis far-field patterns measured at $100 \mathrm{~mA}$ for devices with fixed $\sim 5 \mu \mathrm{m}$-wide narrow shallow ridge and variable wide deep-etched ridges (the widest beam corresponds to devices with $10-\mu \mathrm{m}$-wide deep ridge). (d) Modal gain spectra measured at several currents below threshold for three-stage cascade lasers with 5 - $\mu$ m-wide shallow and $10-\mu \mathrm{m}$-wide deep ridges. 
The far-field pattern corresponding to the single-step shallow ridge is only approached for a wide deep ridge width above $\sim 30 \mu \mathrm{m}$ (Figure $4 \mathrm{c}$ ) when lateral current spreading substantially increases the device threshold (Figure $4 \mathrm{~b}$ ). Devices with $10-\mu \mathrm{m}$-wide deep-etched ridges generated beams with slow axis far-field divergence angle above 20 degrees at full width at half maximum due to a strong lateral confinement of the modal field. Figure $4 \mathrm{~d}$ plots modal gain spectra measured at different currents below the threshold for lasers with a 10- $\mu$ m-wide deep-ridge section. The internal loss of about $9-10 \mathrm{~cm}^{-1}$ can be estimated from the long-wavelength part of the gain spectra-only about $2-3 \mathrm{~cm}^{-1}$ above the values measured for 100- $\mu \mathrm{m}$-wide single-step deep-etched reference lasers. Thus, the strong lateral confinement of the laser mode reinforced by deep etching does not generate excessive optical loss. This observation is also reflected in rather similar efficiencies of $100-\mu \mathrm{m}$-wide broad-stripe and narrow-ridge lasers (Figure $4 \mathrm{~b}$ ). The injection efficiencies of wide- and narrow-ridge devices are estimated to be $\sim 180 \%$. It should be noted that the etching depth of the narrow shallow ridge is a critical parameter for stable single-spatial-mode operation at high current/power and insufficient etching does not introduce enough loss to prevent excitation of the higher-order modes that are supported in double-step waveguide structures with a wide deep-ridge section. The CW performance of the optimized $\lambda>3-\mu \mathrm{m}$ ridge devices and their operation as tunable external cavity lasers will be reported elsewhere.

\subsection{Devices Emitting near $2 \mu \mathrm{m}$}

To develop a cascade heterostructure compatible with an operating wavelength near $2 \mu \mathrm{m}$, the carrier injectors had to be redesigned compared to those used in 3- $\mu \mathrm{m}$ lasers (Figure 1a). The fundamental absorption edge of the first InAs QWs of an electron injector that defines a minimum wavelength for an efficient laser operation should be adjusted. The injector design used in lasers described in previous sections was expected to introduce a strong absorption loss in a spectral region below $\sim 2.3 \mu \mathrm{m}$. Indeed, the devices with QWs emitting near $2 \mu \mathrm{m}$ and utilizing an AlGaAsSb layer compositionally graded from 50 to $5 \%$ of aluminum and AlSb/InAs electron injector with a 4.2-nm-wide first InAs QW (the design utilized in lasers discussed in previous sections of this paper) were hardly able to start lasing at room temperature. In order to move the injector absorption edge below $2 \mu \mathrm{m}$, the AlSb/InAs electron injector (Figure 1a, insert) was redesigned, and the first InAs QW thickness decreased to $3 \mathrm{~nm}$ (the rest of the chirped superlattice was modified appropriately). The devices based on the new injector design but using an unchanged AlGaAsSb compositionally graded layer demonstrated a reduced threshold and increased efficiency and became comparable to reference double-QW diode lasers at room temperature. A further strong improvement of the laser performance was achieved when initial composition of the AlGaAsSb graded layer was increased to $80 \%$ aluminum, and its doping level was set to nominal $10^{17} \mathrm{~cm}^{-3}$. The addition of the $30-\mathrm{nm}$-thick $\mathrm{Al}_{0.8} \mathrm{Ga}_{0.2} \mathrm{As}_{0.07} \mathrm{Sb}_{0.93}$ constant composition layer just before the 100-nm graded layer led to a further slight increase in device efficiency [16].

Figure 5a shows light-current-power conversion characteristics of $100-\mu \mathrm{m}$-wide, 3-mm-long, coated lasers generating a record $\sim 2 \mathrm{~W}$ of $\mathrm{CW}$ output power from a $100-\mu \mathrm{m}$-wide aperture, as reported in [16] and repeated here for consistency. Devices demonstrated threshold current densities of $\sim 80 \mathrm{~A} / \mathrm{cm}^{2}$, an injection efficiency of $\sim 180 \%$, and a peak power conversion efficiency of $\sim 20 \%$. Double-step ridge waveguide lasers (similar to Figure 4a) with a shallow narrow ridge of the width $(\sim 5 \mu \mathrm{m})$ and a $\sim 14-\mu \mathrm{m}$-wide deep-etched section were fabricated. Figure $5 \mathrm{~b}$ plots pulsed (200 ns/100 kHz) and CW light-current characteristics of AR/HR coated 2-mm-long lasers mounted epi-side-up. Inserts show the SEM image of the as-cleaved facet of the processed laser and slow axis far-field pattern measured at $300 \mathrm{~mA}$. Thanks to a large value of the slope efficiency of the cascade lasers and strong thermal stability, an output power in excess of $150 \mathrm{~mW}$ was achieved without the need for epi-down mounting. The estimated thermal resistance of the epi-up mounted lasers is about $40 \mathrm{~K} / \mathrm{W}$, as determined from a comparison of the spectral shift with temperature and deposited electrical power. The lasers mounted epi-down demonstrated a thermal resistance of about $25 \mathrm{~K} / \mathrm{W}$. 
Clearly, devices mounted epi-down were able to generate higher power levels, and their performance will be reported elsewhere. In this work, we would like to stress that for many applications, the power of the order of $100 \mathrm{~mW}$ in the nearly diffraction-limited beam is ample, and epi-up mounting promotes reliability and an ease of optical alignment. The parameters $T_{0}$ and $T_{1}$ measured in a low-duty cycle regime in a temperature range from 20 to $60^{\circ} \mathrm{C}$ for narrow-ridge devices were about $65-75 \mathrm{~K}$ and $300 \mathrm{~K}$, respectively. The higher values were observed for longer coated lasers. It should be noted that, if the $\mathrm{CW}$ regime is used to determine the parameter $\mathrm{T}_{0}$, the artificially increased values above $80 \mathrm{~K}$ can be obtained.

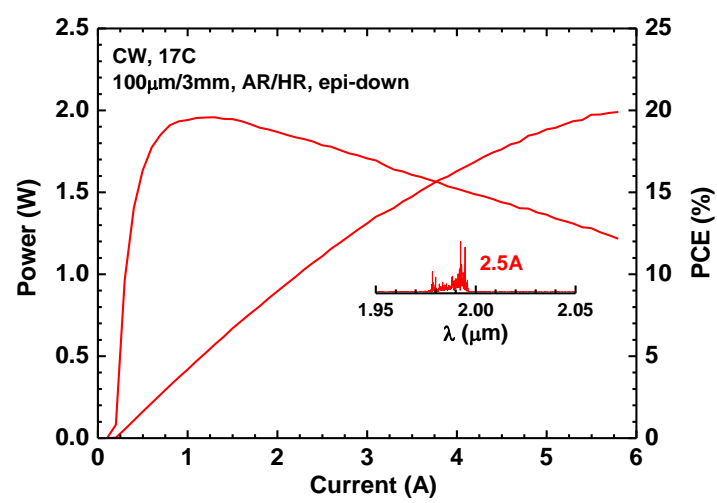

(a)

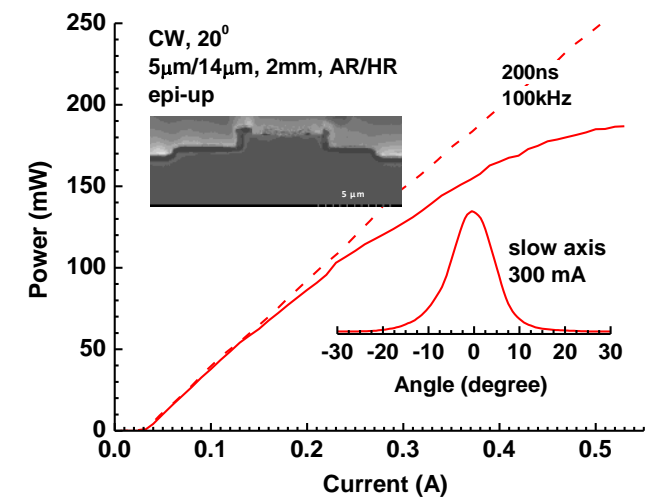

(b)

Figure 5. (a) CW light-current-power conversion characteristics measured at $17^{\circ} \mathrm{C}$ for 100 - $\mu \mathrm{m}$-wide, 3-mm-long anti-/high-reflection (AR/HR) coated two-stage cascade lasers [16]. Insert shows the device's emission spectra. (b) Pulsed (200 ns/100 kHz) and CW light-current characteristics measured at $20{ }^{\circ} \mathrm{C}$ for $5-\mu \mathrm{m}$-/14- $\mu \mathrm{m}$-wide double-step, 2-mm-long, AR/HR coated two-stage cascade lasers mounted epi-side-up. Inserts show the scanning electron microscope (SEM) image of laser facet and measured slow axis far-field pattern.

\section{Conclusions}

Cascade pumping of type-I quantum well gain sections was utilized to increase output power and efficiency of GaSb-based diode lasers operating in a spectral region from 1.9 to $3.3 \mu \mathrm{m}$. The experiment showed that the increase in the number of cascades from two (previously used in record cascade $3-\mu \mathrm{m}$ emitters) to three led to a critical enhancement of the differential gain and a reduction in the threshold current density of lasers where $\lambda>3 \mu \mathrm{m}$. Light p-doping of the AlGaAsSb graded section did not introduce extra optical loss but aided hole transport, as required for the realization of the efficient multi-stage cascade pumping scheme. Corresponding coated three-stage devices with an $\sim 100-\mu \mathrm{m}$-wide aperture and a 3-mm-long cavity demonstrated CW output power of $500 \mathrm{~mW}$ near $3.18 \mu \mathrm{m}$ at $17^{\circ} \mathrm{C}$-a more than twofold increase compared to previous state-of-the-art diode lasers emitting only $200 \mathrm{~mW}$. Three-stage lasers with quantum wells designed to emit in the middle of the methane absorption band near $3.25 \mu \mathrm{m}$ demonstrated record output power levels above $350 \mathrm{~mW}$-a nearly threefold improvement over previous non-cascade state-of-the-art diodes. Utilization of the different quantum wells in a cascade laser heterostructure was demonstrated to yield wide gain lasers, as often desired for tunable laser spectroscopy. Two-step etching was applied in an effort for simultaneous minimization of both the internal optical loss and the lateral current spreading in narrow-ridge lasers. Cascade lasers operating near $2 \mu \mathrm{m}$ demonstrated threshold current densities $\sim 80 \mathrm{~A} / \mathrm{cm}^{2}$ and $\mathrm{CW}$ output power near $2 \mathrm{~W}$ per $100-\mu \mathrm{m}$-wide stripe at room temperature. Corresponding double-step narrow-ridge lasers soldered epi-side-up to copper blocks generated more than $150 \mathrm{~mW}$ in nearly diffraction-limited beam. Further optimization of the geometry of the double-step shallow-/deep-ridge single-spatial-mode devices is expected to yield high-power external cavity and tunable distributed-feedback single-frequency lasers for various spectroscopic applications. 
Acknowledgments: The work was supported by US Army Research Office, grant W911NF1110109, and the National Science Foundation, grant ECCS-1408126.

Author Contributions: Leon Shterengas and Gregory Belenky developed the concept and designed devices and experiments. Gela Kipshidze performed epitaxial growth. Takashi Hosoda developed fabrication methodologies and characterization protocols. Tao Feng and Meng Wang fabricated and characterized lasers. Leon Shterengas wrote the paper.

Conflicts of Interest: The authors declare no conflict of interest.

\section{References}

1. Kazarinov, R.F.; Suris, R.A. Possibility of amplification of electromagnetic waves in a semiconductor with a superlattice. Fiz. Tekh. Poluprovodn. 1971, 5, 707-709.

2. Capasso, F. High-performance midinfrared quantum cascade lasers. Opt. Eng. 2010, 49, 111102. [CrossRef]

3. Razeghi, M. High-performance InP-based mid-IR quantum cascade lasers. IEEE J. Sel. Top. Quantum Electron. 2009, 15, 941-951. [CrossRef]

4. Vurgaftman, I.; Bewley, W.W.; Canedy, C.L.; Kim, C.S.; Kim, M.; Merritt, C.D.; Abell, J.; Meyer, J.R. Interband cascade lasers with low threshold powers and high output powers. IEEE J. Sel. Top. Quantum Electron. 2013, 19, 1200210. [CrossRef]

5. Lyakh, A.; Zory, P. Gallium-arsenide-based bipolar cascade lasers with deep quantum-well tunnel junctions. IEEE Photonics Technol. Lett. 2006, 18, 2656-2658. [CrossRef]

6. Yang, R.Q.; Qiu, Y. Bipolar cascade lasers with quantum well tunnel junctions. J. Appl. Phys. 2003, 94, 7370-7372. [CrossRef]

7. Sanchez, D.; Cerutti, L.; Tournié, E. Mid-IR GaSb-based bipolar cascade VCSELs. IEEE Photonics Technol. Lett. 2013, 25, 882-884. [CrossRef]

8. Yang, R.Q. Infrared laser based on intersubband transitions in quantum wells. Superlattices Microstruct. 1995, 17,77-83. [CrossRef]

9. Shterengas, L.; Liang, R.; Kipshidze, G.; Hosoda, T.; Belenky, G.; Bowman, S.S.; Tober, R.L. Cascade type-I quantum well diode lasers emitting $960 \mathrm{~mW}$ near $3 \mu \mathrm{m}$. Appl. Phys. Lett. 2014, 105, 161112. [CrossRef]

10. Liang, R.; Hosoda, T.; Shterengas, L.; Stein, A.; Lu, M.; Kipshidze, G.; Belenky, G. Narrow ridge $\lambda \approx 3 \mu \mathrm{m}$ cascade diode lasers with output power above $100 \mathrm{~mW}$ at room temperature. IEEE Photonics Technol. Lett. 2015, 23, 2425-2428. [CrossRef]

11. Hosoda, T.; Fradet, M.; Frez, C.; Shterengas, L.; Sander, S.; Forouhar, S.; Belenky, G. Laterally coupled distributed feedback cascade diode lasers emitting near $2.9 \mu \mathrm{m}$. IET Electron. Lett. 2016. [CrossRef]

12. Jiang, Y.; Li, L.; Yang, R.Q.; Gupta, J.A.; Aers, G.C.; Dupont, E.; Baribeau, J.-M.; Wu, X.; Johnson, M.B. Type-I interband cascade lasers near $3.2 \mu \mathrm{m}$. Appl. Phys. Lett. 2015, 106, 041117. [CrossRef]

13. Li, R.; Li, J.; Shterengas, L.; Jackson, S.D. Highly efficient holmium fibre laser diode pumped at $1.94 \mu \mathrm{m}$. IET Electron. Lett. 2011, 47, 1089-1090. [CrossRef]

14. Forouhar, S.; Briggs, R.M.; Frez, C.; Franz, K.J.; Ksendzov, A. High-power laterally coupled distributed-feedback GaSb-based diode lasers at $2 \mu \mathrm{m}$ wavelength. Appl. Phys. Lett. 2012, 100, 031107. [CrossRef]

15. Hosoda, T.; Wang, M.; Shterengas, L.; Kipshidze, G.; Belenky, G. Three stage cascade diode lasers generating $500 \mathrm{~mW}$ near $3.2 \mu \mathrm{m}$. Appl. Phys. Lett. 2015, 107, 111106. [CrossRef]

16. Hosoda, T.; Feng, T.; Shterengas, L.; Kipshidze, G.; Belenky, G. High power cascade diode lasers emitting near $2 \mu \mathrm{m}$. Appl. Phys. Lett. 2016, 108, 131109. [CrossRef]

17. Shterengas, L.; Belenky, G.L.; Kim, J.G.; Martinelli, R.U. Design of high-power room-temperature continuous-wave GaSb-based type-I quantum-well lasers with lambda $>2.5 \mu \mathrm{m}$. Semicond. Sci. Technol. 2004, 19. [CrossRef]

18. Belenky, G.; Shterengas, L.; Kipshidze, G.; Hosoda, T. Type-I diode lasers for spectral region above $3 \mu \mathrm{m}$. IEEE J. Sel. Top. Quantum Electron. 2011, 17, 1426-1434. [CrossRef]

19. Hosoda, T.; Liang, R.; Kipshidze, G.; Shterengas, L.; Belenky, G. Room temperature operated diffraction limited lambda $\sim 3 \mu \mathrm{m}$ diode lasers with $37 \mathrm{~mW}$ of continuous-wave output power. IET Electron. Lett. 2013, 49, 667-669. [CrossRef] 
20. Forouhar, S.; Borgentun, C.; Frez, C.; Briggs, R.M.; Bagheri, M.; Canedy, C.L.; Kim, C.S.; Kim, M.; Bewley, W.W.; Merritt, C.D.; et al. Reliable mid-infrared laterally-coupled distributed-feedback interband cascade lasers. Appl. Phys. Lett. 2014, 105, 051110. [CrossRef]

21. Bachmann, A.; Kashani-Shirazi, K.; Arafin, S.; Amann, M.-C. GaSb-based VCSEL with buried tunnel junction for emission around $2.3 \mu \mathrm{m}$. IEEE J. Sel. Top. Quantum Electron. 2009, 15, 933-940. [CrossRef]

(c) 2016 by the authors; licensee MDPI, Basel, Switzerland. This article is an open access article distributed under the terms and conditions of the Creative Commons Attribution (CC-BY) license (http:/ / creativecommons.org/licenses/by/4.0/). 